\title{
Unidade de Terapia Intensiva Pediátrica: expectativas e Sentimentos dos Pais da Criança Gravemente Enferma
}

\author{
Pediatric Intensive Care Unit: Expectations and Feelings of \\ parents of seriously ill children
}

\author{
CARINA OLIVEIRA PÊGO' \\ MARCELAMILREAARAÚJO BARROS²
}

\section{RESUMO}

Objetivo: Compreender as expectativas e os sentimentos dos pais durante a internação do filho gravemente enfermo na Unidade de Terapia Intensiva Pediátrica. Materiais e métodos: O estudo consiste de uma pesquisa de abordagem qualitativa com enfoque fenomenológico. As informações foram coletadas por meio de entrevista semiestruturada no período de março a abril de 2014 e foram analisadas pelo método análise de conteúdo. Participaram desse estudo 10 genitores de um hospital público no Município de Porto VelhoRO. Resultados: Os resultados apontam que os membros familiares são a base para o enfrentamento da doença para os pais que estão com seu filho internado. Os fatores religiosidade e espiritualidade também se compõem como suporte, a fé e a esperança ajudam a aliviar a dor e o sofrimento além de ser motivo de expectativas em relação à cura. Conclusão: Os sentimentos descritos pelos pais são de desespero, de impotência, de dor, medo, angústia, de muitas dúvidas quanto ao diagnóstico e prognóstico, incapacitando-os no desenvolvimento de suas atividades diárias. Ao mesmo tempo em que os genitores associam a UTI com a doença grave e a morte, suas expectativas se alicerçam na consciência de que esta unidade também é o local de recuperação e reencontro com a vida, com demonstração de confiança em quem cuida do seu filho.

\section{DESCRITORES}

Unidade de Terapia Intensiva Pediátrica. Pais. Criança.

\begin{abstract}
Objective: To understand the expectations and feelings of parents during hospitalization of seriously ill child in the Pediatric Intensive Care Unit. Material and Methods: This was a qualitative study with phenomenological approach. The information was collected through semi-structured interviews from March to April 2014 and analyzed by the content analysis method. A total of 10 parents participated in this study in a public hospital in the city of Porto Velho-RO. Results: The results show that family members are the basis for coping with the disease for parents who are with their hospitalized children. Factors such as religiousness and spirituality were associated with support, whereas faith and hope help to relieve pain and suffering as well as drive expectations for healing. Conclusion: The feelings described by the parents were related with despair, helplessness, pain, fear, anguish, many doubts about the diagnosis and prognosis, incapacitating them to develop their daily activities. While the parents associate the ICU with serious illness and death, their expectations are rooted in the awareness that this unit is also the site of recovery and reunion with life, with demonstration of confidence in the one who takes care of their child.
\end{abstract}

DESCRIPTORS

Unit Pediatric Intensive Care. Parents. Child.

Graduada em Enfermagem pela Faculdade Interamericana de Porto Velho-UNIRON, Porto Velho, Rondônia, Brasil.

2 Mestre. Docente do Curso de Enfermagem. Faculdade Interamericana de Porto Velho - UNIRON. Porto Velho, Rondônia, Brasil. 
$\mathrm{A}$ existência da doença do filho faz com que a família entre em um mundo novo definido por diversos sentimentos como o medo, a ansiedade e a culpa. A hospitalização, sobretudo na Unidade de Terapia Intensiva Pediátrica (UTIP), é configurada como um momento de muito estresse e temor, contudo é comum a família relacionar a internação em UTI com a proximidade da morte ${ }^{1}$.

O significado de ter um filho internado na UTI é uma ruptura em sua estrutura, caracterizada pela separação e deslocamento entre os membros da família. É a criança na UTI, os pais no hospital, os outros filhos em casa. Com a criança internada na UTI, a família deparase com barreiras que a impossibilitam de permanecer com o filho, cuidando e protegendo como sempre o fez ${ }^{2}$.

A hospitalização começa a ser uma vivência repugnante por estabelecer métodos de perdas, independente do período de duração e da idade. Porém as crianças são excessivamente mais vulneráveis, visto que esta circunstância repercute de maneira direta no seu desenvolvimento, isto é, no seu sistema evolutivo, requerendo profunda acomodação nas mudanças que acometem seu dia a dia ${ }^{3}$.

Para a família, a hospitalização na UTI é caracterizada pelo alto grau de ansiedade e estresse, gerados pela gravidade clínica do paciente e pelas limitações na comunicação intrínsecas ao ambiente. Essa hospitalização pode trazer aos familiares a existência de desconfortos que serão percebidos por alterações, perturbações e dificuldades de natureza física, psíquica e social e que ameaçam a sua integridade como ser biopsicossocial, seu relacionamento interpessoal e sua capacidade de enfrentamento da situação $0^{4,5}$.

O interesse pelo estudo surgiu após as práticas hospitalares em Unidades de Terapia Intensiva, onde despertou interesse em se conhecer as vivências e sentimentos dos pais com seus filhos internados nessas unidades, buscando identificar também como os genitores se comportam diante dessa situação, quais os métodos que utilizam para se manterem firmes e confiantes na recuperação do seu filho.

Nesse contexto objetivamos identificar as expectativas e os sentimentos dos pais durante a internação do filho gravemente enfermo na Unidade de Terapia Intensiva Pediátrica (UTIP) em um Hospital público do Sistema Único de Saúde no município de Porto Velho-RO.

\section{MATERIAS E MÉTODOS}

Trata-se de uma pesquisa de cunho científico, com abordagem qualitativa, utilizando-se do enfoque fenomenológico. A pesquisa foi realizada na Unidade de Terapia Intensiva Pediátrica do Hospital Infantil Cosme e Damião, um hospital público no município de Porto Velho, Estado de Rondônia.

$\mathrm{O}$ instrumento inicial para a coleta de dados constituiu-se inicialmente de artigos científicos. Após a anuência da direção do órgão e pelos participantes deste estudo, foram agendados horários e local exclusivo para realizar a pesquisa, com a aplicação do segundo instrumento para coleta de dados, que compreendeu em entrevista semiestruturada. O mesmo aconteceu na sala de espera do setor UTI Pediátrica.

As entrevistas foram realizadas no período de março e abril de 2014, sendo respondidas pelos pais ou genitores das crianças internadas na unidade intensiva pediátrica. $\mathrm{O}$ roteiro das perguntas foi composto por nove questões abordando assuntos referentes a expectativas e sentimentos dos genitores no processo de internação dos seus filhos.

Para a análise e interpretação dos dados, realizamos a análise de conteúdo dentro das perspectivas de Bardin em que as informações gravadas foram transcritas na íntegra e os resultados confrontados com a literatura pertinente. A análise de conteúdo consiste em um conjunto de técnicas de análise das comunicações, tendo em vista métodos sistemáticos e objetivos de descrição do conteúdo das mensagens, indicadores (quantitativos ou não) que consintam na indução de conhecimentos relativos às condições de produção ou eventualmente de recepção destas ${ }^{6}$.

$\mathrm{Na}$ apresentação dos resultados, para garantir o anonimato dos genitores, os mesmos foram identificados por nomes de pedras preciosas, cuja participação se inclui nos parâmetros contidos na Resolução 466/12 do Conselho Nacional de Saúde/ Ministério da Saúde. Essa pesquisa só foi realizada após aprovação pelo Comitê de Ética em Pesquisa em Seres Humanos das Faculdades Integradas Aparício Carvalho - FIMCA com o Parecer n. ${ }^{\circ} 610.854$.

\section{RESULTADOS E DISCUSSÕES}

Participaram desse estudo 10 genitores, sendo 8 (oito) mães e 2 (dois) pais. Das mães entrevistadas, todas destinavam seu tempo ao cuidado da família e seus afazeres domésticos. Os pais exerciam atividades ligadas ao trabalho braçal.

Os relatos evidenciam que os membros familiares constituem em um enorme suporte para os genitores que estão com seus filhos internados, alem dos fatores como religião e espiritualidade que também compõem um importante apoio para os pais no 
enfrentamento da doença, uma vez que a fé e a esperança podem ajudar a aliviar a dor e o sofrimento da família ocasionada pela apresentação da doença no cotidiano, além de ser motivo de expectativas em relação à cura.

Partindo desses conceitos concretizamos a análise do conteúdo a fim de compreender a experiência dos genitores que vivenciam esse fenômeno, ter sua criança gravemente enferma internada na Unidade de Terapia Intensiva Pediátrica. Com ênfase nos relatos expressos durante a coleta de dados, categorizamos a análise nas seguintes temáticas: Sentimentos Vivenciados pelos pais diante da hospitalização na Unidade de Terapia Intensiva Pediátrica (UTIP); Mudanças no ambiente familiar decorrente à internação do filho; Estratégias utilizadas para enfrentar a hospitalização e a relação entre pais e profissionais de saúde ao longo da hospitalização da criança na UTIP.

\section{Sentimentos Vivenciados pelos pais diante da hospitalização na Unidade de Terapia Intensiva Pediátrica (UTIP)}

Ter um filho hospitalizado em uma unidade de terapia intensiva pediátrica é descrito pelos pais, como uma ocasião muito difícil, de medo, desespero e angústia. Foram sentimentos destacados pelos pais que adquirem as características de pais participativos no cenário hospitalar, destacando a unidade de cuidados intensivos pediátricos. Observam-se sentimentos de desespero e tristeza nas falas:

"Desespero, a gente se sente tão incapaz, inútil, tão impossibilitada entendeu a gente se ver sem força praticamente pra lutar entendeu, é o sentimento que toda mãe tem, ela sente como se parece que o pedacinho dela tá indo embora entendeu é isso que eu sinto". (PÉROLA)

"Foi o pior dia da minha vida, ai eu senti um aperto tão grande no meu coração eu pensava que nunca mais ia ver meu filho quando ele veio pra cá, desespero total". (SAFIRA)

"Ai me sentir assim em pânico, muito angustiada, me deu uma coisa ruim, eu fiquei assim muito triste, muito triste, com medo de perde ele”. (CRISTAL)

A internação do filho na UTIP induz os genitores a vivenciar angústias, aflições e medos. Ao enfrentar esta situação, os pais colocam em jogo seus sentimentos e emoções que se confrontam com o caráter que assume na família e na sociedade e, neste turbilhão de emoções, esperam dar sequência ao seu ser no mundo, tentando conciliar o que sentem com o que pensam e com o que tem de fazer ${ }^{7}$.

A hospitalização da criança é vista pelos pais como uma experiência complexa e triste, que provoca desespero e dor psíquica. A dor relaciona-se ao episódio de ter um filho doente e hospitalizado, incapacitando-o no desenvolvimento de suas atividades diárias. A doença pode gerar nos genitores sentimentos de insegurança e dúvidas ${ }^{8}$.

Pais experimentam o receio, ansiedade e insegurança. Esses sentimentos emergem de situações que acompanham a internação, tais como: a probabilidade da morte do filho, a procura de informação sobre a condição de saúde do filho e a própria dinâmica de trabalho da terapia intensiva, com sua tecnologia e com o saber característico dos profissionais ${ }^{7}$.

A possibilidade de não poder acompanhar seu filho ao longo de sua hospitalização é compreendida ainda como um fator desencadeador do medo, tão presente no ambiente de cuidados intensivos. Os sentimentos que os pais expõem com o adoecimento e internação deve-se ao universo desconhecido do hospital e da unidade intensiva, cujas regras e rotinas, muitas vezes são rigorosas e diferem do cotidiano familiar. Isso fica evidente nas falas:

"Só faz três dias que ele tá aqui né, ai eu venho pra cá só nesse horário posso fica aqui ate cinco horas só”. [...] então eu vou pra casa com medo de o telefone tocar, com medo de receber uma noticia ruim, mas é normal né, normas do hospital. (CRISTAL)

"Olha eu fiquei desesperada quando fui informada que eu não poderia ficar com ela, é difícil você deixar sua filha no hospital [...] mais eu respeito os limites que a instituição colocar né, se eles estão impondo isso é por algum motivo que eles tem para que as coisas funcionem corretamente né". (ESMERALDA) [...] Quando ele subiu pra cá eu me desesperei comecei a pensar eu não vou conseguir eu não, não vou conseguir deixar ele aqui sozinho. (SAFIRA)

Garantir a permanência dos genitores de maneira contínua junto à criança diminuem os traumas gerados à criança e os pais ficam mais tranquilos, pois estão vendo de perto o que está acontecendo com seu filho9.

O primeiro impacto da hospitalização na vida familiar é a separação física de um de seus membros, já que interrompeu a vida em conjunto, impedindo a continuidade das suas atividades habituais ${ }^{5}$. 
A internação em UTI é sempre uma ocasião difícil para os familiares, pois eles se sentem forçados a entregar seu ente querido a outros, àqueles que detêm um saber específico para agir nessa ocasião ${ }^{10}$.

Percebe-se que nas falas anteriores existe apreensão, sofrimento e angústia, em contrapartida os genitores apresentam esperança e expectativa de um milagre da melhora do quadro.

“Melhoras! Sem duvidas, eu tenho que pensar positivo, não posso pensar que ele vai piorar eu tenho que pensar que ele sempre está melhorando!"

A presença da família, em especial da mãe, geralmente requer e cultiva a inter-relação criança, equipe, família, paralisa os resultados negativos decorrentes da separação, desenvolve sua acomodação ao hospital, promove a aceitação do tratamento e ameniza os fatores estressantes da doença, dos processos e da hospitalização ${ }^{11}$.

A dúvida em relação à melhora da criança faz com que os genitores visualizem a possibilidade do agravamento da doença e também a morte do filho. O temor é o sentimento identificado e verbalizado com frequência, e tem características como inquietação, incerteza, desespero e receio ${ }^{8}$.

\section{Sentimentos expressos ao ver o filho gravemente enfermo na UTI}

A internação de um integrante da família principalmente de um filho no ambiente de cuidados intensivos gera nos pais múltiplos sentimentos negativos como tristeza, saudade e também determinadas incertezas quanto ao cuidado. Ao mesmo tempo, essa circunstância também gera sentimentos positivos, como a esperança da melhora no quadro de saúde da pessoa internada e a confiança de que no final tudo vai dar certo.

O ambiente da UTI pode constituir como uma ameaça à família, pois os mesmos se encontram em um local totalmente diferente e desconhecido, mostram assim um conceito de quebra da interdependência afetiva e emocional entre seus componentes.

A maioria dos genitores entrevistados compreende que a UTI é uma unidade em que prevalecem maiores recursos, onde aparelhos e equipamentos são eficazes para a sobrevivência do seu filho, visto que as crianças internadas na UTI estão em situação delicada e grave e com risco iminente de morte.

Nos relatos a seguir os pais referem ainda, que confiam que é nessa unidade de tratamento que seu filho está mais bem cuidado, já que a atenção é ininterrupta, uma vez que a equipe está mais próxima e em alerta constante, sendo isso o fator que suscita segurança para os genitores. Tais fatos são expostos nas seguintes falas:

"Todo mundo corre risco independente de estar na UTI ou não tudo pode acontecer, mas na UTI é pra algo muito grave, grave vai pra UTI por que precisa de um tratamento intensivo de um cuidado intensivo eu tenho consciência disso. [...] As pessoas acham que vai morrer, pra mim não UTI é um lugar que precisa de tratamento constantemente". (DIAMANTE)

"Ai assim depois que eu passei a vim todos os dias pra cá, eu passei a entender que minha filha precisa fica aqui, aqui todo mundo cuida dela, cuidam assim toda hora sabe". (ESMERALDA)

Após vivenciar e distinguir melhor a unidade de terapia intensiva, os pais começam a reconhecer e a identificar o valor que este ambiente tem para uma completa recuperação do filho que se encontra ali dependente do ambiente. Os genitores passam a enxergá-la como o local melhor organizado e preparado para receber e cuidar de seu filho nesse momento delicado e dessa forma, garantir a sobrevivência nesse estado grave de saúde ${ }^{12}$.

Fica claro que os pais reconhecem que a internação de um filho é uma situação difícil, afirmam ainda que muitas vezes sentem-se abandonados, com mínimas informações acerca do estado de saúde do filho bem como chocados com a circunstância, na qual o temor e a angústia se enfrentam com o desconhecido ${ }^{13}$.

Nesse estudo podemos observar ainda que ao mesmo tempo em que os genitores associam a UTI com a doença grave e de morte, eles percebem que esta unidade também é como local de recuperação e reencontro com a vida. Fato este que pode ser apreendido nas seguintes falas:

"[...] estou mais tranquilo agora do que quando estava na emergência, então aqui o tratamento fica, mas intensivo fica, mas forte, ficou melhor, então agora sim agora eu to totalmente tranquilo". (JADE)

"Meu sentimento era como se eu tivesse perdendo ele, como se ele não fosse mais sair daqui, fosse sair morto, mas depois reverteu meu sentimento mudou por que eu comecei a confiar e acreditar que a UTI é o melhor lugar pra ele nesse momento." (ESMERALDA). 
A UTI gera nos familiares anseios, receios, incertezas e agonia, mas por outro lado, os familiares expõem sentimentos positivos e de confiança, sentindose mais protegidos por deixar seu ente em um ambiente melhor equipado e acreditando que o mesmo possa ser melhor cuidado e assistido pelos profissionais de saúde.

Esse ambiente pode ser configurado com um local menos hostil, com mais acolhimento, sendo compreensivo com aquele momento de fragilidade. Mas para que isso aconteça, os familiares necessitam perceber que o lugar mesmo que temeroso oferece serviço de qualidade, permitindo aos familiares a tranquilidade de assistência intensa 24 horas $^{14}$.

Ao entrar nessa unidade pela primeira vez, os genitores apresentam um misto de sensações, dentre as quais, a visão de uma criança não saudável, cercado de aparelhos. Esse momento é definido pelos pais como um momento muito doloroso.

"Dói muito ver seu filho naquela cama espetado de tudo quanto é lado, com um tubo enfiado de garganta abaixo, doe bastante, mas só que eu sei que é pro bem dele, e pra ajudar na recuperação dele, no tratamento dele, então a gente tem que superar essa dor e acreditar, confiar na UTI e na equipe". (PÉROLA)

"Dói, dói tanto ver ele ali daquele jeito, com tubo, sedado, ai só de pensar dói, mais e pra recuperação dele, ele precisa tá aqui". (JADE)

A UTI talvez seja o ambiente que mais provoque desconforto e estresse nos genitores, mas, também pode ser o setor que favoreça a recuperação e a reabilitação de pacientes em estado grave e críticos. Os pais expõem sentimentos contraditórios em relação à UTI, abrangendo-a como lugar que provoca medo, mas, ao mesmo tempo, que proporciona segurança e esperança de recuperação para seu ente querido ${ }^{15}$.

As falas evidenciam que as famílias vivenciam mitos sobre esse setor, pois os familiares revelam diversas experiências negativas de pessoas próximas.

"A gente pensa muita coisa, por que a gente fica ouvindo né a primeira coisa que acontece né, tem muita gente em volta que diz a meu parente morreu disso, meu parente passou por isso é foi pra UTI morreu." (JADE)

"Quando meu filho veio pra cá, fiquei desesperada por que comecei a ouvir pessoas falar que tinha alguém conhecido que passou por isso, e depois morreu ai assim a gente se sente insegura, com medo, assim com medo de meu filho morre". (ESMERALDA)

Em geral a população possui uma visão estereotipada do ambiente, vinculada à ideia de sofrimento e morte. No entanto, em contraposição, ao mesmo tempo esforçam-se para considerar os aspectos positivos do setor. Geralmente a família muda de concepção no momento em que passa a conviver no setor, conhecendo assim o extenso trabalho da equipe multiprofissional ${ }^{9}$.

\section{Mudanças no ambiente familiar decorrente à internação do filho}

A existência da doença e internação do filho dentro da UTIP foi marcada, segundo relatos dos pais entrevistados, pela intensa transformação no cotidiano familiar, alterando os papéis, em prol da permanência constante de um deles no ambiente hospitalar. Os afazeres habituais são redirecionados entre os componentes da família e novos papéis são exercidos no ambiente familiar durante o período de ausência dos pais, em particular da genitora. Os pais, na maioria das vezes têm dificuldades para gerenciar os compromissos e as obrigações que adquirem principalmente relacionados ao trabalho conforme os relatos a seguir:

"Muda o ambiente, muda à rotina por que ate então eu acordava ja ia trabalhar no outro dia do mesmo jeito fazia minhas atividades normais, agora um dia vou um dia falto, ta difícil eu tenho que ver meu filho e também tenho que trabalhar". (PEROLA)

"Mudou minha rotina dentro de casa ta assim, tudo muito bagunçado assim eu fico mais aqui do que em casa né então mudou muita coisa bagunçou tudo" (ESMERALDA).

A necessidade da internação da criança é um acontecimento desagradável tanto para ela quanto para a família, pois causa uma alteração no convívio familiar, independente do período de hospitalização, constituindo modificações na rotina diária. Ressaltamos ainda que a instabilidade da criança não atinge somente a família que se encontra nesse ambiente, mas também pode envolver todo o contexto direta ou indiretamente envolvidos ${ }^{16}$.

Podemos observar nesse estudo que os outros filhos também experimentam modificações na vida, que podem ser causadoras de sofrimento, além de serem cuidados por diversos membros do círculo familiar. 
"Mudou muito eu tenho mais dois filhos, uma dia fica na casa de um, um dia no outro, no começo eu com minha mãe às vezes com minha Irma, tenho que deixar eles todo dia com alguém diferente." (SAFIRA)

"Mudou tudo, eu tenho que deixar minha filha de dois anos com os outros, apesar de ser a vó dela e a vó dela cuida muito bem dela né,o pai dela trabalha só chega de noite ai tenho que deixar. (CRISTAL)

Com a hospitalização do filho enfermo, os genitores que têm outros filhos se sentem obrigados a deixá-los a cuidado de outros membros familiares causando assim uma quebra de união familiar ${ }^{17}$.

Assim, a família vivencia uma oscilação de reorganização de suas tarefas diárias, decorrentes da repercussão das demandas provocadas. Esse grupo passa por intensas transformações, modificando o equilíbrio do circulo familiar, pois a preferência é a recuperação da saúde do filho hospitalizado e "todo" o restante é deixado em segundo plano. As narrativas abaixo assim o revelam:

"Abrir mão de tudo deixei a casa do jeito que tinha deixado não liguei como ela ta ou deixou de ficar foquei somente no meu filho na melhora do meu filho." (DIAMANTE).

"Agora minha vida é direcionada somente pra ele to aqui de manha to aqui de tarde to aqui de noite né, o momento que for necessário eu vou fica aqui com ele" (PÉROLA).

Para que os pais, e, em especial a mãe consiga conciliar seus afazeres cotidianos, ela tem que muitas vezes dividir-se entre o filho hospitalizado e os demais membros que estão em casa, ocasionando uma tempestade de sentimentos. Apesar de levarem dessa experiência uma série de conhecimentos, carregam ainda muitas dúvidas e temores quanto à sua capacidade para lidar com a situação ${ }^{9}$.

O relacionamento entre os componentes familiares também passa por uma transformação com a hospitalização da criança. E se desenvolve em muitas situações, uma maior aproximação, na tentativa de sustentar o laço familiar, ainda que diante da distância física.

"Então o ambiente familiar melhorou eu diria que 100\% houve uma melhora, houve uma mudança, aproveitamos para colocar os nossos pensamentos em dias pra gente observamos olhas mais um pro outro a gente se fortalecer aproveitar pra ta pertinho pra gente fazer uma corrente bem forte" (JADE). [...] o relacionamento com a família mudou muito minha família ficou muito unida graças a Deus eu tenho uma família maravilhosa assim abençoada mesmo ne, e ta me ajudando ta me apoiando todo mundo ta se unindo cada vez mais por que o objetivo é a melhora dele. (DIAMANTE)

Os pais afirmam que esse momento é uma etapa da vida em que a família procura permanecer ainda mais unida, pois, é a ocasião em que é necessário unir as forças em prol da saúde e do bem-estar do paciente internado na UTI, e se torna a atitude mais compreensível de enfrentar tal situação ${ }^{18}$.

Neste contexto, observamos que a vida conjugal que também se modifica, tornando complexo conciliar o cuidado aos outros filhos e a atenção à criança hospitalizada.

[...] eu tenho uma menina de 4 anos então mudou muita coisa, pai e mãe teve que se dividir pra poder amparar todos os dois eu aqui com ele, e ele lá cuidando da menina.(PEROLA)

[...] Deixei meu esposo mais duas filhas uma de 16 outra de 17 elas ficaram lá, mais nós estamos bem unidos ne mais união”. (RUBI)

À medida que os recursos financeiros e emocionais esgotam-se, os genitores sentem-se sofrendo uma pressão social e vão retomando suas atividades. O pai volta a trabalhar, pois precisa do dinheiro para continuar mantendo a família ${ }^{19}$.

\section{Estratégias utilizadas para enfrentar a hospitalização}

No decorrer da hospitalização da criança gravemente enferma, os genitores perdem o controle do funcionamento das suas rotinas, é algo imprevisto que acaba desestruturando o núcleo familiar. Notou-se de uma forma marcante que a religiosidade e espiritualidade são descritas pelos genitores como uma forma de consolo durante esse período vulnerável, contudo é caracterizada como uma busca de força superior para amenizar o sofrimento causado pela hospitalização do filho.

\footnotetext{
"Eu sou uma pessoa religiosa, Eu confio muito em Deus, Eu me apego a ele, Eu oro entrego meu filho nas mãos dele e acredito no poder dele, meu filho vai sair dessa”... Eu creio. (DIAMANTE)
} 
"A minha estratégia é eu procuro buscar Deus cada dia né, cada dia ler mais a bíblia, por que sem Deus nós não somos nada né, essa é minha única estratégia e ta funcionando graças a Deus". (SAFIRA)

"A estratégia que eu utilizo no momento é [...] a Minha fé em Deus, é o que tá me fortalecendo todos os dias minha fé é em Deus outra estratégia eu não tenho somente em Deus". (ESMERALDA)

Os genitores procuram na fé uma estratégia de superar a situação que estão enfrentando, e mencionam que a experiência de se ter um filho na UTI é extremamente difícil provocando assim muita ansiedade. Essa é uma maneira que respectivamente contribuirá para a permanência dos genitores dentro do ambiente que considera ser temeroso. A fé em Deus é uma evidente solução para desviar-se do desespero e garantir adaptação e aceitação perante o desfecho da condição de saúde do seu filho ${ }^{8}$.

A família vivencia um período difícil, são experiências de dor, desespero e angústia diante dessa situação. Os genitores devem buscar estratégias que os ajudem a vivenciar esse momento tão complexo como apoiar um ao outro, para assim, enfrentar esse momento doloroso ${ }^{17}$.

A relação entre pais e profissionais de saúde ao longo da hospitalização da criança na UTIP

Assim como a criança, os pais também se encontram com dificuldades no enfrentamento da conjuntura causada por um adoecimento. Nessa perspectiva, os pais revelam experiências positivas no hospital quando se sentem incentivados para desenvolver o cuidado à criança tornando-os capazes de cuidar. Por isso, valorizam a equipe pelo cuidado ofertado a seu filho.

Vale ressaltar que na UTIP existe uma equipe multidisciplinar, tais como médicos, enfermeiros, fisioterapeutas, psicólogos e técnicos de enfermagem. Logo, é necessário que essa equipe crie um bom relacionamento e vínculo com as famílias, para que as necessidades das mesmas sejam atendidas e a interação com a equipe seja satisfatória. Desta forma, pode-se adquirir uma maior confiança aumentando a satisfação dos familiares e dos pacientes. Os genitores podem contribuir para a recuperação da criança.

Os depoimentos mostraram reconhecimento pela atenção e carinho que os acompanhantes receberam de alguns profissionais.
"Muito Boa, muito boa não tenho do que reclamar, meu relacionamento é ótimo com eles, não tenho nada a reclamar só elogiar, por que no dia que eu cheguei aqui com ele me trataram super bem, trataram muito bem o meu filho, foram prestativos o tempo todo, não falta um medico, todo tempo ali junto dele, orientando, observando, as enfermeiras muitos cuidadosas. (PÉROLA)

"Excelente, excelente! aqui não parece profissionais, aqui a gente ver assim quase uma família, um apoiando o outro, levanta é assim mesmo, fé em Deus além dos conhecimentos profissionais que médicos e enfermeiros tem nesse local tem a parte de humanização interna é muito bom é importante". (OPALA)

"Bem, to sendo bem correspondida com todos". (RUBI)

Os genitores dentro da UTIP serão mais ou menos autônomos, a partir das orientações recebidas da equipe de saúde que atende a criança. Quanto mais orientada a respeito do diagnóstico, tratamento e estado clínico do seu filho, maior será a probabilidade deles entenderem precocemente suas alterações. Para que isso ocorra os pais precisam ser incentivados pelos profissionais da equipe a participar no cuidado à criança dando apoio às suas ações e ensinando-lhes os cuidados necessários ${ }^{19}$.

Podemos evidenciar no decorrer das entrevistas, que os pais se sentem bem orientados sobre as rotinas do setor e sobre o que está acontecendo com o seu filho. Revelam ainda, ter sido bem acolhidos, respeitados e também cuidados pela equipe multidisciplinar.

"Me sinto bem orientada ate por que eu peço pra ele me falar a verdade, então eu creio que ele fala a verdade pra mim então eu me sinto bem orientada eu sinto". (ESMERALDA)

"A equipe daqui me passou com bastante clareza todas as informações é eu então eu to bem orientado a equipe toda ta trabalhando bem e qualquer duvida que eu tenho eu procuro o, alguém da equipe competente pra responder minha pergunta”.(JADE)

Acreditamos na importância da presença do genitor no cuidado ao paciente grave, no entanto, surgem diversas expectativas e dúvidas que necessitam ser sanadas. A equipe multidisciplinar deve está sensível às necessidades do familiar, vários aspectos devem ser 
esclarecidos, pois, desde a manifestação da doença até o estabelecimento do diagnóstico e do prognóstico, acontecem crises e desajustes, e estes precisam se sentir apoiados e seguros, com suas dúvidas devidamente esclarecidas $^{12}$.

Nessa pesquisa notou-se ainda que os genitores sentem dificuldade em acompanhar os procedimentos que a equipe multidisciplinar realiza diariamente na criança internada. Os pais revelam tristeza ao ver o filho naquela situação.

"Ai eu me sinto assim é, me sinto triste, assim que mãe sofre junto com o filho ali ne, mãe sofre acho que mais de ver o filho ali naquela situação.(CRISTAL)

"Quando elas começam assim a mexer nele e me sinto muito mal por que as vezes ele fica agoniado né então eu me sinto mal ao mesmo tempo que elas começam a fazer alguma procedimento nele ate eu saio de perto pra não ver, mais quando eu to perto ele ta bem, eu sinto que ele ta bem então eu me sinto bem com ele ali, mais quando começa esse procedimento eu me sinto mal." (ESMERALDA)

A presença do familiar nessa ocasião é essencial, servindo de apoio ao paciente e aos profissionais de Saúde, pois admitem resgatar as crenças, valores e informações diversas sobre o doente, cooperando para seu tratamento e recuperação ${ }^{20}$.

Em contrapartida, os genitores se revelam felizes quando acompanham os procedimentos realizados pela equipe, pois acreditam que tudo o que a equipe realiza com a criança é necessário para a sobrevivência da mesma. As falas abaixo demonstram gratidão à equipe multidisciplinar:

"Feliz, sabe por quê? por que eu sei que ali dentro tem uma equipe toda cheia de amor, comprometida com que faz, entendeu que dedica seu tempo pra cuidar dos nossos filhos, eu sinto muita gratidão por cada um, ali dentro naquela equipe”. (PEROLA)

"Eu só tenho a agradecer a essa equipe, eu agradeço a Deus por que se não fosse eles cuidando do meu aqui, quem iria cuidar? Quem? Então eu só tenho a agradecer". (OPALA)

O setor que encontra laços entre família e profissionais deixa de ser um lugar de conflitos e passa a ser um ambiente capaz de motivar esperança nas famílias. No entanto, o que compreendemos nos serviços de saúde é a dificuldade de programar tal proposta, pois envolve um projeto direcionado às famílias para que se concretize a integralização e humanização do cuidado. Muitos profissionais ainda atendem apenas a criança como componente a ser cuidado, não reconhecendo a família na recuperação do paciente ${ }^{7}$.

A importância da visita aberta e da presença e da mãe é de suma importância para manter essa relação, e a influência desta no desenvolvimento físico e emocional se fazem indispensáveis para sustentar o vínculo afetivo durante o período de hospitalização dessa criança ${ }^{21}$.

Dentro da UTI Pediátrica do hospital de estudo, essa realidade não é diferente, o setor dispõe de um horário de visita aberta que acontece diariamente das 12:00 as 18:00 horas. O Hospital acredita na força de pais presentes, uma vez que eles exercem papel importante na recuperação da criança internada, no entanto, não possuem uma estrutura física segura e confortável e por esse motivo, não permitem a permanência em tempo integral de um dos genitores no decorrer da hospitalização, abrindo-se espaço com algumas exceções quando a área de isolamento não está ocupada, permitindo quando possível, a presença de um familiar em tempo integral. $\mathrm{Na}$ necessidade da realização de procedimentos com os quais os pais ou visitantes não estejam acostumados, a equipe da unidade solicita que os mesmos aguardem na sala de espera.

Vale ressaltar que é realizado um controle na liberação dos visitantes, evitando multidão junto ao leito, cuja atividade é denominada "humanização". Depois de orientados, são dirigidos até o leito da criança. O enfermeiro e o médico de plantão disponibilizam-se para prestar qualquer informação referente à criança, e diariamente é entregue um boletim médico contendo informações sobre o estado clínico do paciente, que é usado para fornecer informações à família pessoalmente, fora dos horários de visita. No momento da admissão, os genitores são informados da rotina do setor e que a equipe da UTI não dará informações pelo telefone a quaisquer que sejam os familiares solicitantes. Em caso de agravamento do quadro, o enfermeiro ou a equipe de humanização ou psicologia entra em contato e solicita a presença dos pais ou responsáveis para maiores informações.

\section{CONCLUSÃO}

A UTIP é um local destinado a crianças que por algum motivo necessitam de cuidados intensivos, 
sendo separados dos pais, transformando a estrutura familiar. A notícia da internação desperta nos genitores sentimentos variados agregados com o medo da morte. Acreditamos que esse receio só poderá ser superado quando as pessoas conseguirem maiores informações sobre esta unidade, como seu funcionamento, suas recomendações e os procedimentos realizados.

Esse estudo proporcionou conhecimentos e informações sobre as expectativas e os sentimentos dos pais que acompanham os filhos no processo de adoecer e hospitalização dentro da Unidade de Terapia Intensiva Pediátrica, consolidando a necessidade em se manter o laço familiar, ressaltando a importância da presença dos genitores dentro da unidade para uma recuperação mais acelerada.

É importante resaltar a importância da equipe multidisciplinar em especial do enfermeiro dentro da UTIP, pois o mesmo estabelece um relacionamento de confiança com a família, a fim de incentivar e motivar os genitores a retirarem todas as suas dúvidas de forma a satisfazer a necessidade de informações, desse modo, diminuir a angústia e o sofrimento de todos os envolvidos.

Por isso é tão importante que os enfermeiros e demais profissionais de saúde constituam um bom relacionamento com os pacientes e suas famílias a fim de identificar seus sentimentos, ansiedades e expectativas para poder ajudá-los na busca de recursos disponíveis para o enfrentamento da crise vivida.

$\mathrm{O}$ estudo nos proporcionou conhecer mais de perto as maneiras e os métodos que os genitores utilizam para permanecerem firmes diante da internação do seu filho e conhecer a mudança do cotidiano da família diante desse novo processo que eles estão enfrentando. Em relação aos genitores, encontramo-los rodeados de diversos sentimentos como assustados, angustiados e impotentes.

Os genitores necessitam estar inseridos no tratamento integral da criança hospitalizada, não exclusivamente com visitas constantes, mas com a participação ativa em determinados procedimentos. Esta participação suavizaria a insegurança e o receio, e manteria o vínculo dos pais com o filho enfermo, proporcionando a livre expressão de sentimentos, com respeito como cada núcleo familiar enfrenta tal situação, contribuindo para a transmissão de força, amor, proteção, carinho e segurança à criança. Estes pequenos gestos representam mais que muitos potentes medicamentos.

Além da inserção do conceito de humanização e sua relação com a família e a criança gravemente enferma, o estudo poderá, ainda, contribuir como experiência para a realização de novos estudos relacionados ao tema, servindo como amparo para discussões e comparações entre as realidades de outras regiões do estado e do país.

\section{REFERÊNCIAS}

1. Hayakawa LY, Marcon SS, Higarashi IH. Alterações familiares decorrentes da internação de um filho em uma unidade de terapia intensiva pediátrica. Rev Gaúcha Enferm., Porto Alegre (RS). 2009; 30(2):175-82.

2. Bousso RS, Angelo M. Buscando preservar a integridade da unidade familiar: a família vivendo a experiência de ter um filho na UTI. Rev. esc. enferm. USP. 2001; 35(2): 172179.

3. Morais GSN, Costa SFG. Experiência existencial de mães de crianças hospitalizadas em Unidade de Terapia Intensiva Pediátrica. Rev. esc. enferm. USP. 2009; 43(3): 639-646.

4. Costa JB, Felicetti CR, Costa CRLM, Miglioranza DC, Osaku EF, Versa GLGS et al. Fatores estressantes para familiares de pacientes criticamente enfermos de uma unidade de terapia intensiva. J. bras. psiquiatr. 2010; 59(3): 182-189.

5. Freitas KS, Mussi FC, Menezes IG. Desconfortos vividos no cotidiano de familiares de pessoas internadas na UTI. Esc. Anna Nery. 2012; 16(4): 704-711.

6. Bardin L. Análise de conteúdo. Lisboa, Portugal. Edição 70; 2009.

7. Souza ABG, Angelo M. Buscando uma chance para o filho vir a ser: a experiência do pai na UTI. Rev. esc. enferm. USP. 1999; 33(3): 255-264.

8. Wyzykowski C, Santos RS. A reação materna diante da internação do filho na terapia intensiva pediátrica: contribuições para a prática da enfermagem. Rev Soc Bras Enferm Ped. 2007; 7(2):15-22.

9. Almeida MI, Molina RCM, Vieira TMM, Higarashi IHMSS. O ser mãe de criança com doença crônica: realizando cuidados complexos. Esc. Anna Nery. 2006; 10(1): 3646.

10. Fonseca RV, Kawaguchi SLD, Silva VA, Freire SC, Filócomo FRF. Sentimentos dos pais acompanhantes de crianças internadas em unidade de terapia Intensiva pediátrica. XII Encontro Latino Americano de Iniciação Científica e VIII Encontro Latino Americano de PósGraduação - Universidade do Vale do Paraíba; 2008.

11. Molina RCM, Varela PLR, Castilho AS, Bercini LO, Marcon SS. Presença da família nas unidades de terapia intensiva pediátrica e neonatal: visão da equipe multidisciplinar. Esc Anna Nery Rev Enferm. 2007; 11(3):437-44.

12. Risso ACMCR, Braga EM. A comunicação da suspensão de cirurgias pediátricas: sentimentos dos familiares envolvidos no processo. Rev. esc. enferm. USP. 2010; 44(2): 360-367.

13. Bettinelli LA; Erdmann AL. Internação em unidade de terapia intensiva e a família: perspectivas de cuidado. Avances en Enfermería. 2009; 27(1): 15-21. 
14. Mendes VJ, Paraíso MKA, Andrade BTL, Mourão XGL. Sentimentos vivenciados por familiares de pacientes internados no centro de terapia intensiva adulto. Rev Cubana Enfermer. 2013; 29(1): 18-28.

15. Costa Filho RC, Costa JLF, Gutierrez FLB, Mesquita AF. Como implementar cuidados paliativos de qualidade na unidade de terapia intensiva. Rev. bras. ter. intensiva. 2008; 20(1): 88-92.

16. Gomes GC Oliveira PK. Vivências da família no hospita durante a internação da criança. Rev. Gaúcha Enferm. 2012; 33(4): 165-171.

17. Othero MB, Carlo MMRP. A família diante do adoecimento e da hospitalização infantil: desafios para a terapia ocupacional. Prat Hosp. 2006; 8(47):100-4.

18. Camponogara S, Santos T, Rodrigues I, Frota L., Amaro D, Turra M. Perceptions and needs of relatives of patients hospitalized in an intensive care unit. Revista De Pesquisa: Cuidado é Fundamental Online. 2013; 5(4): 622-634.

19. Santos QN. Estratégia de enfrentamento (comping) da família ante um membro familiar hospitalizado: uma revisão de literatura brasileira. Advances in Health Psychology. 2013; 21(2):40-47.
20. Pinto JP. Procurando manter o equilíbrio para atender suas demandas e cuidar da criança hospitalizada: a experiência da família [dissertação]. São Paulo: Departamento de Enfermagem da Universidade Federal de São Paulo; 2004

21. Freiberger JS, Jung SI. O psiquismo materno e as estratégias de enfrentamento na primeira internação hospitalar da criança. 2010. Taquara: FACCAT, RS; 2011.

\section{Correspondência}

Marcela Milrea Araújo Barros

Rua José Vieira Caúla, 5301, Residencial Marina, Casa 10. Igarapé - Porto Velho - Rondônia - Brasil - 76824-335 E-mail:mmilrea@hotmail.com 